\title{
THE COST BENEFIT ANALYSIS OF LOW-CARBON TRANSPORTATION DEVELOPMENT OPPORTUNITIES FOR THE 2020-2030 EU PROGRAMMING PERIOD
}

\author{
Author(s): \\ Cs. Fogarassy ${ }^{1}-$ B. Horvath ${ }^{1}-$ A. Kovacs ${ }^{2}$
}

\author{
Affiliation: \\ ${ }^{1}$ Climate Change Economics Research Centre, Szent István University, Gödöllö, Hungary \\ 2Department of Operations Management and Logistics, Szent István University, Gödöllö, Hungary
}

\section{Email address:}

fogarassy.csaba@gtk.szie.hu, horvath@carbonmanagement.hu, kovacs.attila@gtk.szie.hu

\begin{abstract}
Within the European Union's climate policy, transportation qualifies as one of the most significant sectors since it is responsible for $20 \%$ of total GHG (greenhouse gas) emissions. In the 2005-2020 period, the EU is expected to emit a total of 90 $\mathrm{MtCO} 2 \mathrm{e}$. Although this figure qualifies as a $12 \%$ decrease in terms of total volume, $80 \%$ of it cannot be regarded as cost efficient; in fact, the majority of these emissions fall into the highest $\mathrm{CO}_{2 \mathrm{e}}$ avoidance cost category within the European Union. However, Hungary is in an exceptional situation, as the cheap potential for reducing emissions is significantly higher than the EU average. Hungary is presently one of the countries best performing its 2020 climate policy targets, since its GHG emissions resulting from past years' production is still far behind the "emission baseline" threshold defined on the basis of production in the 1980's. Due to slow and controversial development, Hungary's vehicle park will continue to show a significant dependency on fossil fuels (gasoline, diesel) in 2030. It should be noted that this situation could endanger the long term (2050) commitments for GHG reductions. The aim of the present study was to examine the environmental and financial effects of development projects that contribute to the restructuring of the transport sector and the attaining of climate policy targets as well as implementing these developments in the most cost effective manner possible.
\end{abstract}

\section{Keywords}

low-carbon, green transport, cost-benefit analysis, climate policy, transport strategy

\section{Introduction}

According to forecasts, Hungary will continue to show a large degree of dependency on fossil fuels (gasoline and diesel) by 2030 [1]. The international studies performed regarding the sector provide a good indication of the fact that the sector's structure does not presently support climate-friendly or low carbon development principles [2]. The reason is that most investments will never enjoy a return (due to under-utilization and the structural defects of the public transport sector), causing possible significant damages and negatively effecting welfare $[3,4]$. The present study uncovered the parameters of the possibilities for Hungary's transport sector for
2020 and 2030. Based on the previous analyses performed by the authors, the most important sectoral indicator of the reduction of transport emissions is the change in the ratio of public transportation to private transport [5] as well as the general structure of goods transport [6]. Subsequent studies will therefore deal with the possible tools for maintaining the level of public transportation at its current level of $20-21 \%$ despite of decreasing tendencies, and how such measures can provide a financial return $[7,8]$. The most important issue in the case of goods transport is identifying the modes of transport that are worth developing in the interest of simultaneously attaining both emissions reduction and increases in cost efficiency without incurring additional costs for society, for example through the amortization of the road system at an increased rate $[9,10]$. It can be established based on previous analyses that the cost effectiveness of large investments within the sector is often questionable [11, 12]. Using the developments implemented in Western Europe, the present study attempts to outline development concepts that build on a greater degree of social activity but emphasize smaller technological investments. An example is the inclusion of electric mopeds in personal transport, which would result in decreasing both GHG emissions and the use of vehicles.

\section{Materials and methods}

The fundamental aim of the study was to develop a system that is suitable for the multipurpose assessment of the effects of interventions at the national economy level. One of the bases of the model is the cost-benefit analysis; the other is multi-targeting. There are several solutions available for managing the latter, but in general they trace decisions back to a simple, single-target decision [13]. The simplest solution for managing multi-targeting is selecting one target from the available targets while considering the remaining targets to be given in the future and to then run the model. The model results are saved and the above steps are repeated for each of the targets previously considered given. This results in a set of solutions which, if illustrated and analyzed, enables the selection of the solution or set of solutions.

Based on the above, the study is based on the following costbenefit analysis equation (1) [14]:

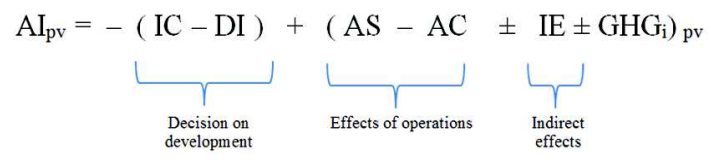


where:

$\mathrm{AI}_{\mathrm{pv}}$ - the present value of additional income

IC - the additional investment cost of the equipment to be purchased (EUR)

DI - possible support and discounts (EUR)

AS - the additional sales revenue resulting from the additional yield or increase in quality attributed to using the given technology (EUR/year)

AC - the balance of the given technology's additional costs and its possible savings (EUR/year)

IE - the indirect economic impacts (environmental effects, effects on society) of using the given technology (EUR/year)

$\mathrm{GHG}_{\mathrm{i}}$ - the indirect effects on emissions of using the given technology, based on the value of the decrease in GHGs as per the EU ETS quota forecast (HUF/year)

pv $\quad-$ present value

The essence of the CBA model developed by the authors can be found in the point entitled "Indirect effects." Similarly to the COWI model, this denotes the value of the quantified externalities generated by the project. Since the aim of the study and the target of the model is to decrease the rate of GHG emissions, the benefits arising from these effects are calculated by integrating them into this part. The basis of this is the forecast of EU ETS quota prices issued for the period ending with 2030 and prepared by the European Union, which was used to quantify the degree to which the $\mathrm{CO}_{2}$ balance changed [15].

In order to be able to perform a credible analysis, the initial technological composition for the given sector (BAU) as included in the basic formula has to be defined. The CBA pertaining to the structural changes can then be performed on the basis of the scenarios compiled for the various periods.

The model is comprised of the following main units:

- Historical datasets

- Scenarios

-Forecasts

- Cost-benefit tables

- Results, vulnerability study

\section{The database used in the study}

The TREMOVE model developed by the Belgian organization called Transport \& Mobility Leuven was used to examine the transport sector from the aspect of climate policy. Their methodology is based on a trend calculation ending with 2030, which analyses the European Union Member States' transport structure and its cost-benefit relationship. The database of the newest version (3.4) is publically available and provides enough information to effectively be applied in the cost-benefit mechanism created by the study.

\section{Research results}

\section{Scenario 1: Maintaining the share of public transportation}

The authors assumed two fundamental cases in their scenarios: in one, processes continue as per the present political and support systems, which literature refers to as "Business As Usual" (hereinafter BAU). In the other case, significant resources were allocated to the sector in the form of a project in the interest of achieving decreases in carbon dioxide emissions. Figure 1 shows that according to the basic scenarios (BAU), the increase in the population's kilometer demands will be accompanied by a proportionate increase in private transport, causing the percentage of public transport to fall as low $15 \%$. Scenario 1 wishes to present the investment needs and development expectations that maintaining the present share of public transport at present levels and increasing it later on entails until 2030. The following Figure shows that public transport will not lose its share within the transport structure (in the Project version) as a result of the developments.

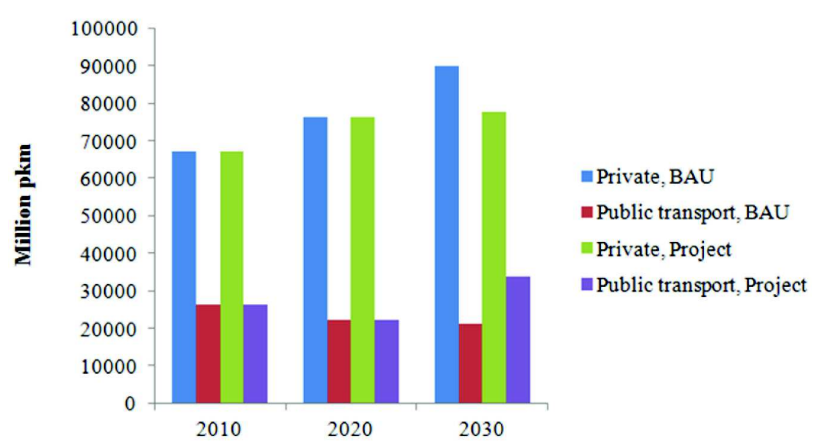

Figure 1. The structure of the transport system Note: Own calculation based on TREMOVE 3.4 model data, 2015

\section{Evaluation of Scenario 1}

The carbon orientation matrix (Figure 2.) presents a summary of the study performed in Scenario 1. It shows the processes that took place within the sector after project implementation, during the studied period. Project placement is indicated by the grey bubble, depending on whether the return curve turned around and whether the results led to a decrease in emissions or to a surplus within the sector. The Figure precisely shows that although the emissions values were decreased, the project run by the study still ended up in the left lower quadrant. This means that the achieving of the set goals requires investments in the transport sector that will not provide a return even over the long term.

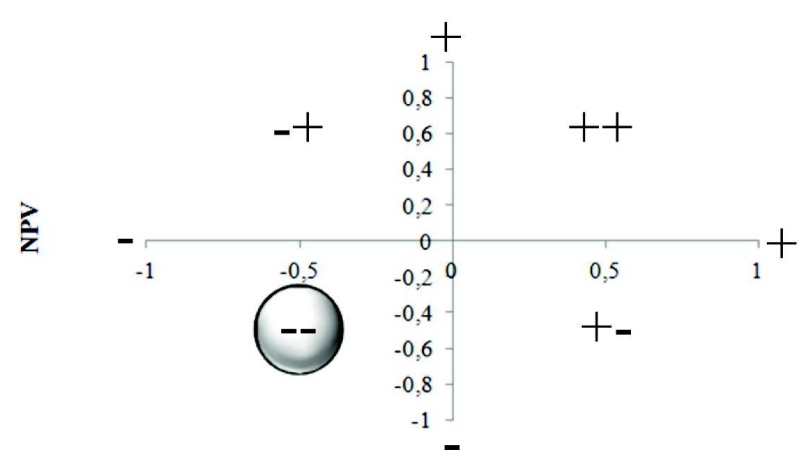

Figure 2. Scenario 1 carbon orientation matrix

Explanation

(1) - + : A project is implemented that increases emissions and the investment does not provide a return within the lifecycle.

(2) ++ : A project where the invested costs show a tendency of providing a return, but the activity itself was not suitable for decreasing GHG emissions.

(3) - - : Emissions can only be decreased with high costs on which there will be no return.

(4) + - : Acceptable scenarios that enable $\mathrm{CO}_{2 \mathrm{e}}$ decreases to be attained while also providing a return on investments over a longer period of time. (Investments that are recoverable even after their lifecycles, with externalities that can change in line with political preferences.) 
Scenario 2: Rerouting heavy goods transport (over 16 tons) from public roads to electric freight trains

The trend of an increasing need in the amount of kilometers travelled was applied in the case of both goods transport and passenger transport (Figure 3.); however, this case attempted to examine the changes in the shares of the various vehicles. It has been clear for some time now that decision makers are using various regulative measures in an attempt to remove transport vehicles with greater capacities (over 16 tons) from the roads as much as possible (by traffic restrictions, introducing combined transport, tolls, etc.) and that they prefer vehicles with smaller payloads [16]. However, the figure below presenting the structure of goods transport clearly shows that in regards to shipped weight, these vehicles, besides to electric freight trains, still make up the majority of this sector. That is why Scenario 2 examines what would happen if the goods they transport would not only be rerouted to vehicles with smaller capacities, but rather towards railway freight traffic. Compared to the BAU version, the project regrouped $20 \%$ of the activity of vehicles exceeding 16 tons to electric freight trains using low carbon technologies by 2030 .

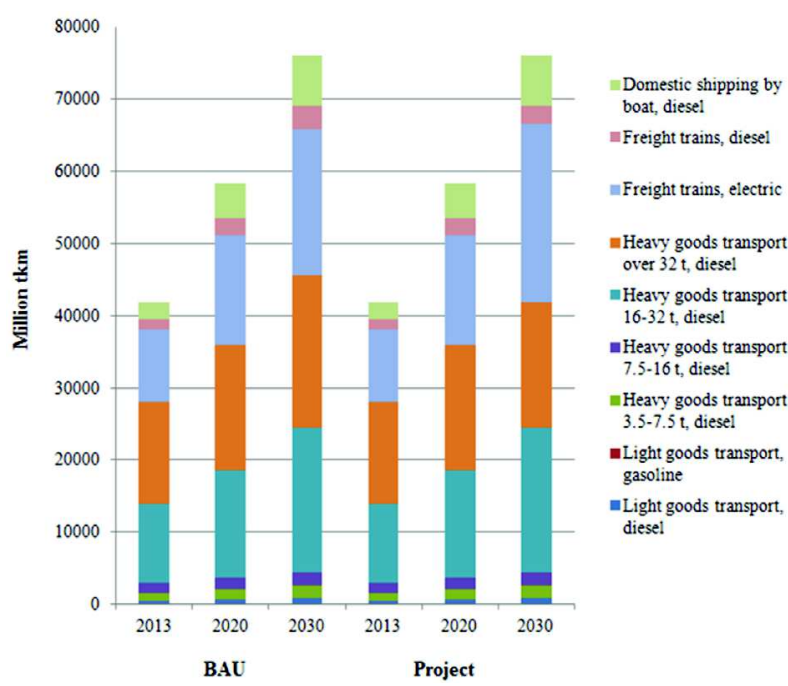

Figure 3. Breakdown of the structure of goods transport according to vehicle types and fuels; Note: Own calculation based on TREMOVE 3.4 model data, 2015

\section{Evaluation of Scenario 2}

As a summary of the above conclusions, it is worth illustrating the results in a carbon orientation matrix (Figure 4.), which shows that, similarly to Scenario 1 the present Scenario is also one that is disadvantageous for Hungary. Its location in the lower left quartile means that GHG reductions could only be attained with serious effort and - as shown by the financial indices - they would not provide a return.

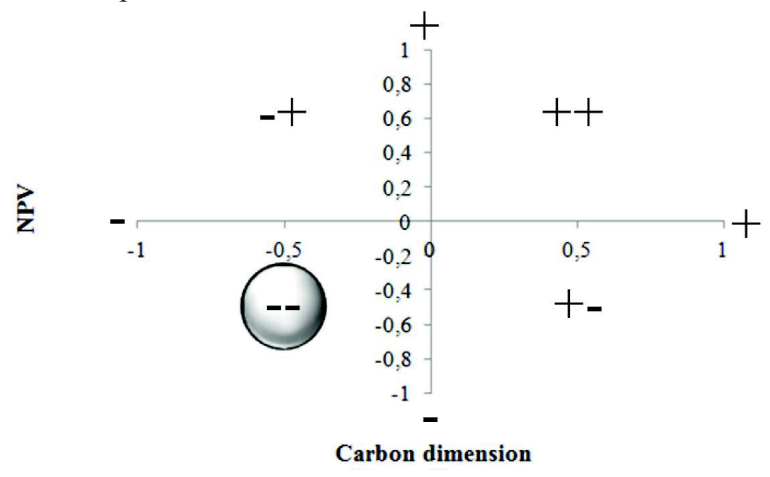

Figure 4. Scenario 2 carbon orientation matrix

\section{Scenario 3: Increasing the share of transport by moped}

In the last scenario, the study examined what would happen if, instead of orientating the BAU variation towards a sectoral approach (as in the case of public transport and goods transport), the study merely increased the rate of a new mode of transport (the moped) within individual transport. The essence of this approach is keeping the trend of the increase in the demand of number of kilometers travelled similarly to the example set by BAU, but decreasing the ratio of passenger vehicles by $5 \%$ and replacing them with mopeds (Figure 5.). Previous experience has shown that the ratio of urban to long distance traffic is one of the main areas requiring development. Urban transport is responsible for the main emissions load in this relationship [17]. Public transport naturally continues to play an important role in this scenario as well; however, it has been shown above that resources should not be invested in public transport, as investments do not provide a return in the sector. Scenario 3 was imagined within the framework of a project in which the populace replaces their passenger vehicles with mopeds, for which the state provides financial support in the form an organized program.

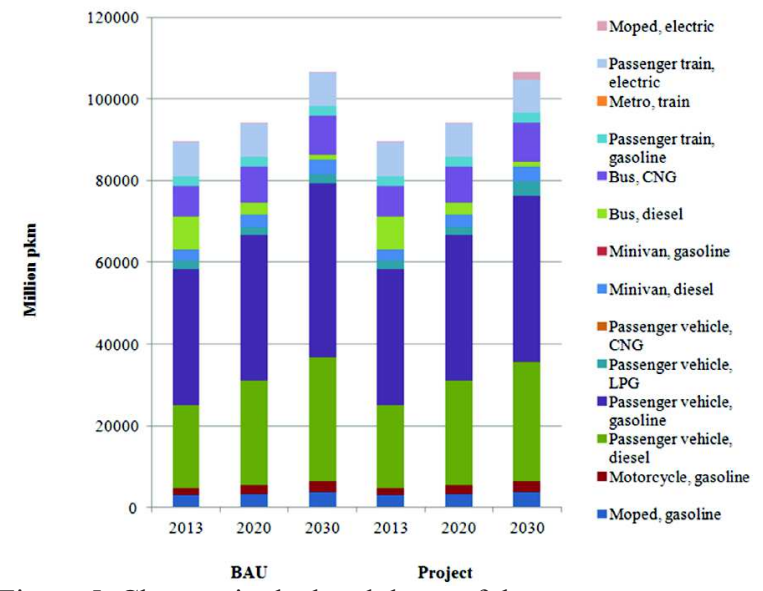

Figure 5. Changes in the breakdown of the passenger transport structure according to vehicle types and fuels until 2030

Note: Own calculation based on TREMOVE 3.4 model data, 2015

\section{Evaluation of Scenario 3}

The project implemented in Scenario 3 holds the ideal position in the carbon orientation matrix (Figure 6.), as it had positive values in both aspects (GHG reduction and financial return). Although the emissions results were not as convincing as the results attained regarding its finances, it has to be taken into account that this approach still presents a better overall picture for solving the problem of urban traffic than the public transport version studied in Scenario 1.

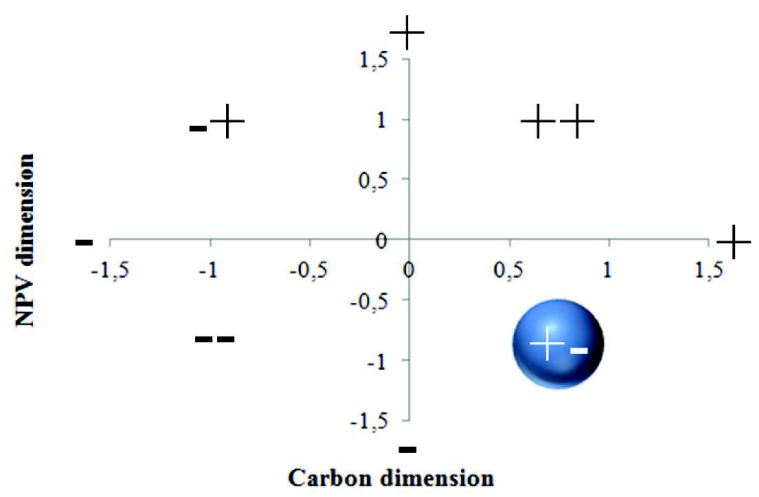

Figure 6. Scenario 3 carbon orientation matrix 
As already described above, the cost and GHG effectiveness of electric mopeds can be further increased by increasing the number of kilometers they are used every day or by expanding the length of time they are used each year (6-7 months instead if 5).

\section{Conclusion}

The analysis consisted of running three projects that aimed at intervening in those areas of the transport sector that, based on previous experience, were considered to be the most important from the aspect of development. The introduced "carbon orientation matrices" fundamentally aim at presenting the financial and carbon reduction aspects of various developments simultaneously. The "relative carbon cost" figure (Figure 7.) was created in order to compare the various scenarios; in it, the three scenarios can be compared to each other. The logic of their placement essentially remained unchanged; however, the sizes of the bubbles play an important role in this figure. Bubble size indicates the resource requirements of the given project: what amount is equal to a savings of $1 \mathrm{t}$ of $\mathrm{CO}_{2 \mathrm{e}}$ in the period between 2020 and 2030 (if the carbon change is negative) or to the emission of $1 \mathrm{t}$ of $\mathrm{CO}_{2 \mathrm{e}}$ in the same period (if the carbon change is positive)

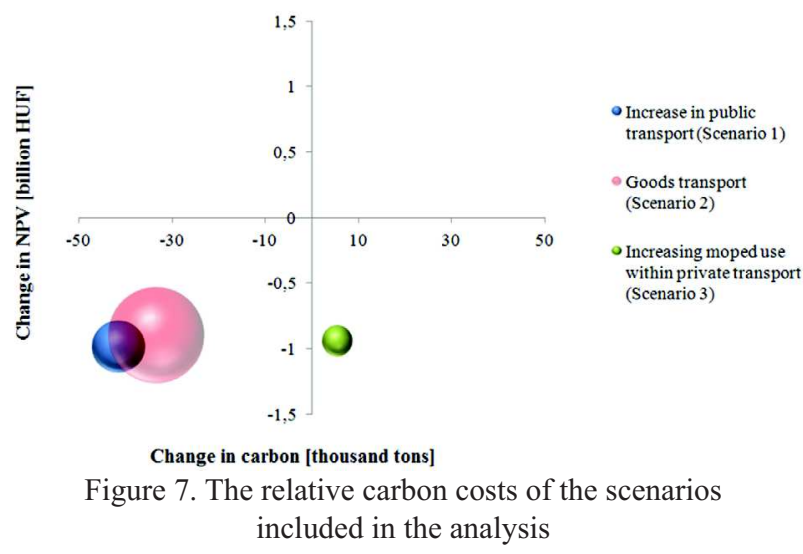

The first goal (Scenario 1) was to maintain the share of public transport at its present value $(20 \%)$, which the BAU forecast shows would significantly decrease until 2030 (to 15-17\%). However, the cost-benefit analysis showed that the cost structure of developing the public transport system in question is not at all efficient and all invested assets are characterized by an NPV curve that does not provide a return. The summary figure also shows that although the large investment requirement is paired with actual emissions reductions, the project would still not provide a financial return within its planned lifecycle.

The second main aspect is the possible development of the goods transport system (Scenario 2), the restructuring of which has been a topic of discussion amongst professional and political decision makers for some time now. Based on the results of the CBAs, it is apparent that replacing heavy vehicles with railway transport is the worst possibility of those included in the study. Surprisingly, Scenario 2 shows a possibility where moving towards a low-carbon solution not only fails to provide a financial return, it is also less effective in reducing emissions than expected. Based on the data, the correct direction that development should take is not using the more expensive (requiring great investments and developments) method of railway freight transport to ship goods, but to continue to use smaller capacity but more mobile vehicles for transport that provide a safe solution and to replace those with low-carbon technologies (i.e. $\mathrm{CNG}$ or electric vehicles). An example is the practice of large European multinational companies, which use heavy goods transport vehicles (exceeding 16 tons; around 20-40 tons) to ship goods to a center and then use smaller vehicles (between 3.5-7 tons) for distribution.

During the elaboration of the electric moped sample project (Scenario 3), the authors wished to establish how the fundamental characteristics of private transport can be affected by the introduction of a relatively simple but environmentally friendly mode of transport. This clearly shows that, compared to previous scenarios, an investment that provides a return (and reduces GHGs) can be made even with the inclusion of significantly less resources. The study included a macro-level examination of the spreading of the selected technology. In the interest of better efficiency, it would be more expedient if the decision makers of large cities could consider the implementation of various large volume developments at the micro level. Based on the results of Scenario 3, it can basically be established that the maintenance and operation issues of the transport sector can be solved in a lowcarbon manner (low-energy use and GHG reduction) with the use of sector-level regulations and the initiation of smaller volume projects primarily in the private sector rather than with the help of large, central investments.

\section{References}

[1.] Forster D., Okamura S., Wilkins G., Morris M., Scott P., Kuikman P., Lesschen J. P., Gardiner A., Boermans T., Grözinger J., Eichhammer W., Reichardt, K.: 2012. Next phase of the European Climate Change Programme: Analysis of Member States actions to implement the Effort Sharing Decision and options for further community-wide measures. AEA group, Harwell, United Kingdom.

[2.] Leduc G., Blomen E.: 2009. Sectoral Emission Reduction Potentials and Economic Costs for Climate Change (SERPECCC), Transport - Passenger cars, road freight and aviation. Ecofys, London, United Kingdom.

[3.] Hill N., Brannigan C., Smokers R., Schroten A., Essen H., Skinner I.: 2012. Developing a better understanding of the secondary impacts and key sensitivities for the decarbonisation of the EU's transport sector by 2050. Final project report. AEA group, Harwell, United Kingdom.

[4.] Borocz M., Horvath B., Herczeg B., Kovacs A.: 2015. Greener cement sector and potential climate strategy development between 2015-2030 (Hungarian case study). Applied Studies in Agribusiness and Commerce-APSTRACT Volume 9. No. 4. pp. 65-74. http://dx.doi.org/10.19041/APSTRACT/2015/4/9

[5.] Fiorello D., De Stasio C., Köhler J., Kraft M., Newton S., Purwanto J., Schade B., Schade W., Szimba E.: 2009. The iTREN-2030 reference scenario until 2030. Deliverable 4 of iTREN-2030 (Integrated transport and energy baseline until 2030). Fraunhofer ISI, Karlsruhe, Germany.

[6.] Coussy P., Portenart P., Afriat M., Alberola E.: 2014. Greenhouse gas emissions in the road transport sector: moving towards inclusion in the European system of $\mathrm{CO}_{2}$ allowances? Energies nouvelles, Lyon, France.

[7.] Dobers K., Klukas A., Lammers W., Laux M., Mauer G., Schneider M.: 2013. Green Logistics: Optimisation Approaches for Resource-Efficient Logistics Services, 2013. pp. 149-161. http://dx.doi.org/10.1007/978-3-642-32838-1_17

[8.] Nemry F.: 2011. Contribution of the transport sector to the objective of the Effort Sharing Decision on non Emission Trading System sectors greenhouse gas emissions. European Commission - Joint Research Centre Notes, Brussels, Belgium.

[9.] Mattila T., Antikainen, R.: 2011. Backcasting sustainable freight transport systems for Europe in 2050. Energy Policy, Volume 39, Issue 3 pp. 1241-1248.

http://dx.doi.org/10.1016/j.enpol.2010.11.051 
[10.] Tsapakis I., Schneider W. H., Nichols, A. P.: 2013. A Bayesian analysis of the effect of estimating annual average daily traffic for heavy-duty trucks using training and validation datasets, s, Transportation Planning and Technology, 36:2, 201-217. http://dx.doi.org/10.1080/03081060.2013.770944

[11.] Borkent B., O'Keeffe S., Neelis M., Gilbert A.: 2012. Costs and Effectiveness of Domestic Offset Schemes, Final report. Ecofys, London, United Kingdom. [12.] Fogarassy Cs., Bakosne B. M.: 2014. Externality analysis of sustainable cattle breeding systems. Hungarian Agricultural
Engineering
Volume
26 ,
pp.
$5-10$.

[14.] Kovacs A.: 2014. A mezőgazdasági vállalatok tervezése a környezeti kölcsönhatások figyelembevételével. Szent István Egyetem, Gödöllő.

[15.] Gohar L. K., Shine K. P.: 2007. Equivalent CO2 and its use in understanding the climate effects of increased greenhouse gas concentrations. Weather, 62: 307-311. http://dx.doi.org/10.1002/wea.103

[16.] Caris A., Macharis C., Janssens G. K.: 2008. Planning in Intermodal Freight Transport: Accomplishments and Prospects , Transportation Planning and Technology, 31:3, 277-302, http://dx.doi.org/10.1080/03081060802086397

[17.] Schade W., Krail M.: 2012. Aligned R\&D and transport policy to meet EU GHG reduction targets. Final Report. Deliverable 7.1 of GHG-TransPoRD (Reducing greenhouse-gas emissions of transport beyond 2020: linking R\&D, transport policies and reduction targets). Fraunhofer ISI, Karlsruhe,

APSTRACT Volume 9. No. 4 pp. 25-32. Germany.

http://dx.doi.org/10.19041/APSTRACT/2015/4/3 